\title{
Effect of orthographic processes on letter identity and letter-position encoding in dyslexic children
}

\author{
Caroline Reilhac ${ }^{1 *}$, Mélanie Jucla ${ }^{2}$, Stéphanie lannuzzi ${ }^{1}$, Sylviane Valdois ${ }^{3}$ and Jean-François Démonet ${ }^{1,4}$ \\ 1 Imagerie Cérébrale et Handicaps Neurologiques, INSERM, UMRS 825, Université Toulouse III Paul Sabatier, Toulouse, France \\ ${ }^{2}$ EA Octogone - Laboratoire Jacques-Lordat (EA 4156), Université Toulouse II Le Mirail, Toulouse, France \\ ${ }^{3}$ Laboratoire de Psychologie et Neuro-Cognition, CNRS, UMR 5105, Université Pierre Mendès France, Grenoble, France \\ ${ }^{4}$ Leenaards Memory Center, CHUV and University of Lausanne, Lausanne, Switzerland
}

Edited by:

Thomas F. Münte, University of Magdeburg, Germany

Reviewed by:

Marcus Heldmann, University

Medical Center SH, Germany

Stefan Heim, RWTH Aachen

University, Germany

\section{*Correspondence:}

Caroline Reilhac, Imagerie Cérébrale et Handicaps Neurologique, INSERM, UMRS 825, Université Toulouse III Paul Sabatier, Pavillon BAUDOT - CHU Purpan, Place du Dr Joseph Baylac, 31059 Toulouse Cedex 9, France. e-mail: caroline.reilhac@gmail.com
The ability to identify letters and encode their position is a crucial step of the word recognition process. However and despite their word identification problem, the ability of dyslexic children to encode letter identity and letter-position within strings was not systematically investigated. This study aimed at filling this gap and further explored how letter identity and letter-position encoding is modulated by letter context in developmental dyslexia. For this purpose, a letter-string comparison task was administered to French dyslexic children and two chronological age (CA) and reading age (RA)-matched control groups. Children had to judge whether two successively and briefly presented four-letter strings were identical or different. Letter-position and letter identity were manipulated through the transposition (e.g., RTGM vs. RMGT) or substitution of two letters (e.g., TSHF vs. TGHD). Non-words, pseudo-words, and words were used as stimuli to investigate sub-lexical and lexical effects on letter encoding. Dyslexic children showed both substitution and transposition detection problems relative to CA-controls. A substitution advantage over transpositions was only found for words in dyslexic children whereas it extended to pseudo-words in RAcontrols and to all type of items in CA-controls. Letters were better identified in the dyslexic group when belonging to orthographically familiar strings. Letter-position encoding was very impaired in dyslexic children who did not show any word context effect in contrast to CA-controls. Overall, the current findings point to a strong letter identity and letter-position encoding disorder in developmental dyslexia.

Keywords: letter-string processing, letter-position encoding, letter-identity encoding, letter transposition, letter substitution, reading acquisition, dyslexic children

\section{INTRODUCTION}

Developmental dyslexia is characterized by a written word identification disorder in children who otherwise exhibit normal intellectual efficiency and have been normally exposed to printed words and literacy instruction. Despite the report of atypical letter identification and letter-order processing during word reading in developmental dyslexia (Salmelin et al., 1996; Grainger et al., 2003; Pernet et al., 2006; Lachmann and van Leeuwen, 2007; Friedmann et al., 2010a,b; Vidyasagar and Pammer, 2010), only a few studies focused on letter identity and letter-order processing abilities in this population. Our purpose in this study was to explore letter identity and letter-order encoding ability in developmental dyslexia and how letter processing is modulated by letter-string context.

Such encoding problems may be related to specific mechanisms within the framework of current reading models. Models of reading acquisition assume that phonological recoding is a key feature of word specific orthographic knowledge acquisition. With time and repetitive exposure to printed words, reading becomes fluent due to direct mapping of the printed word letter string onto its orthographic form in long-term memory. According to the self-teaching hypothesis (Share, 1999; Cunningham, 2006), each successful identification of a new word through phonological decoding provides an opportunity to memorize the whole word orthographic structure. Reading proficiency therefore depends on the child's ability to process word letters in parallel (Aghababian and Nazir, 2000; Bosse and Valdois, 2009). Only a few letters can be processed in parallel at the beginning of literacy instruction but parallel processing abilities increase with print exposure so that proficient readers can process the entire letter string of most words simultaneously (LaBerge and Samuels, 1974; LaBerge and Brown, 1989). Adelman et al. (2010) showed that, in adult readers, letter identity encoding starts during the first $25 \mathrm{~ms}$ of printed word processing on all string positions simultaneously. He however showed that although processing was initiated over the whole word letter string in parallel, all letters were not identified at the same level of efficiency so that multiple fixations are usually observed when reading longer (e.g., Radach et al., 2004) or less frequent (Ferrand and New, 2003; Valdois et al., 2006) words. Reading acquisition thus evolves from serial encoding of sub-lexical orthographic units (i.e., slow letter-by-letter decoding) to a more efficient parallel processing of the entire word sequence.

Bosse and Valdois (2009) reported that the reading performance of typically developing children (from 1st to 5th grade) 
was predicted not only by their phonological skills but also and independently by their visual attention span abilities, i.e., their visual simultaneous processing abilities. In this study, two global and partial letter report tasks were used to assess visual attention span abilities. In both conditions, a horizontal array of five unrelated consonants (e.g., F H T M D) was displayed for $200 \mathrm{~ms}$. Participants were asked to verbally report either the identity of all identified letters (global report condition) or the identity of a single post-cued letter (partial report condition). The children's visual attention span was found to increase with age and reading experience. It was further found to predict both word and pseudo-word reading accuracy, thus suggesting a role of simultaneous processing in the encoding of relevant sub-lexical and lexical orthographic units (Valdois et al., 2004). Using the same two tasks, a visual attention span disorder was found in a subset of dyslexic children, who for most of them showed no phonological disorder (Bosse et al., 2007). These dyslexic children suffer from a simultaneous processing disorder, which prevents them processing as many letters in parallel as non-dyslexic children do. The visual attention span disorder hypothesis thus points to a pre-orthographical disorder (Dubois et al., 2007, 2010) in developmental dyslexia that affects normal identity encoding within letter strings.

Abstract letter identity is likely to represent the basic perceptual unit of visual word recognition (Besner and McCann, 1987). However, letter-position encoding is further required to distinguish words that share the same letters but in different relative positions, as "CAUSE" and "SAUCE." Different types of models aimed to accommodate letter-position encoding within strings, such as the SOLAR model (Davis, 2001), the SERIOL model (Whitney, 2001, 2008; Whitney and Lavidor, 2005), and the Overlap model (Gomez et al., 2008). Although the basic mechanisms of how letter position is encoded differ across these models (e.g., via the activation of open bigrams in the SERIOL, via a spatial coding in the SOLAR model, or via a noisy perceptual input in the overlap model), they all assume that transposed-letter neighbors like "casual" and "causal" are perceptually very similar. Indeed, letter-position encoding within briefly presented letter strings can sometimes be problematic even for skilled readers as shown by the transposed-letter effect in word - e.g., TRIAL read TRAIL - and "migratable" pseudo-word reading - i.e., pseudo-words in which transposition of middle letters can create an existing word; e.g., JUGDE read as their transposed counterpart JUDGE (Andrews, 1996; Perea and Lupker, 2004; Acha and Perea, 2008). Such errors are also reported in young and intermediate readers (Acha and Perea, 2008; Perea and Estévez, 2008) but they tend to diminish with age. Castles et al. (2007) explored developmental changes in the tuning of lexical word recognition processes using a masked priming lexical decision task. The non-word primes were formed by transposing two letters (e.g., lpay-PLAY) or by substituting one letter (orthographic control: rlay-PLAY) of the target words. The performance of skilled adult readers was compared with that of developing readers who were first assessed in Grade 3, then again in Grade 5. Grade 3 readers showed substantial substitution and transposition priming effects. However when tested again in Grade 5 , the same children no longer showed any substitution priming effect, but transposed-letter priming remained. Skilled adult readers showed none of these priming effects. These findings suggest that both letter identity and letter-position encoding evolve with age and reading acquisition. Moreover, the transposed-letter priming effect is observed on both words and pseudo-words, suggesting that it occurs at a pre-lexical orthographic stage (Grainger et al., 2003; Perea and Lupker, 2004). However and despite the report of mis-ordering errors in dyslexic individuals (Terepocki et al., 2002), only a few studies investigated letter-position encoding in developmental dyslexia.

Friedmann and Rahamim (2007) reported that some dyslexic children may develop a selective deficit of letter-position encoding within words (such as reading "broad" for "board"), even in the absence of presentation time constraint. They called this disorder "Letter-Position Dyslexia." In these subjects, anagrams like "trail" and "trial" can no longer be discriminated from each other. Such letter-position errors are described in the context of preserved letter identity and in the absence of between-word migration errors (Friedmann and Gvion, 2001, 2005; Friedmann and Rahamim, 2007). Such selective impairment suggests the existence of a letterposition encoding mechanism that is distinct from letter identification (Ellis and Young, 1988; Friedmann et al., 2010a). However, no study to date has systematically explored both letter-identity and letter-position encoding in developmental dyslexia.

Besides, it is well established that letter identification is strongly influenced by orthographic context. Fast word recognition involves high-level "top-down" influences that have been highlighted through the "Word Superiority Effect" (WSE). The WSE reflects a process whereby letter identity is inferred following word recognition. It was first described by Cattell (1886) who showed that people are able to report more letters from briefly presented words than non-words (i.e., unreadable consonant strings, e.g., "SDTHR"). Reicher (1969) and Wheeler (1970) subsequently showed that a letter is better recognized in word context than in isolation. Since then, the WSE has been exhaustively studied using the Reicher-Wheeler paradigm in different orthographic contexts (e.g., McClelland, 1976; McClelland and Rumelhart, 1981; Estes and Brunn, 1987; Grainger and Jacobs, 1994; Grainger et al., 2003). Studies revealed the existence of related phenomenon such as the Pseudo-word Superiority Effect (PSE). The PSE refers to the fact that expert readers are more accurate at recognizing letters when embedded in pseudo-words (i.e., orthographically regular, pronounceable but meaningless letter sequences) than in illegal unpronounceable non-words (Grainger and Jacobs, 1994; Grainger et al., 2003). Young readers show both a WSE and a PSE but these effects are weaker than in adults (Chase and Tallal, 1990; Grainger et al., 2003). In many studies, the PSE was reported for pseudo-word primes that differed from real words by a single letter (e.g., TOBLE designed from TABLE). This design made interpretation of the results difficult as misperception of primes might have led to confuse them with the source word. In such a case, the PSE should in fact reflect a WSE (Grainger et al., 2003). Alternatively, the PSE may result from increased familiarity of letter combinations (i.e., orthotactics) in pseudo-words (Ziegler and Jacobs, 1995; Hooper and Paap, 1997).

Grainger et al. (2003) investigated whether or not dyslexic children with a phonological disorder exhibited such WSE or PSE on letter identification. They reported a significant PSE in this population as in chronological age and reading age controls. This finding 
suggests facilitatory effects of orthotactic constraints on letterstring processing in both dyslexic children and typically developing children. However, none of the three groups of children showed a WSE, which was only found in adults. While the effect of orthographic context on letter identification is well acknowledged in young readers (Reitsma, 1983; Feitelson and Razel, 1984; Chase and Tallal, 1990; Sprenger-Charolles et al., 1998; Grainger et al., 2003) and to a lesser extent in dyslexic children (Chase and Tallal, 1990; Grainger et al., 2003), whether orthographic context also affects letter-position encoding in dyslexic children compared to normal readers remains an open question.

A first originality of the current study was to assess both letterposition and letter-identity encoding abilities in dyslexic children and how orthographic context modulates these two abilities. We used a letter-string comparison task in which letter position and letter identity were manipulated through the transposition (e.g., RTGM vs. RMGT) or substitution (e.g., TSHF vs. TGHD) of two letters. Stimuli were non-words, pseudo-words, or words in order to explore the influence of orthographic context on letter encoding (letter position and letter identity). Stimuli were carefully designed so that item category remained unchanged after letter substitution/transposition. A second originality of the current study was to focus on a group of dyslexic children with a visual attention span disorder. In preventing parallel processing of letter strings, such disorder is expected to impact both letter identification and letter-position processing. Moreover, performance would be sensitive to sub-lexical units more than word units, so that a PSE but no WSE is predicted in the dyslexic population. The performance of dyslexic children was compared with that of two groups of normal readers matched for chronological or reading age.

\section{MATERIALS AND METHODS PARTICIPANTS}

Thirty-six French native children participated in this study. The dyslexic group was composed of 12 children ( 3 girls; mean chronological age $=10.9$ years, $\mathrm{SD}=0.7$, range: $9.6-12$; mean reading age $=7.5$ years, $\mathrm{SD}=0.7$, range: $6.7-8.6$ ) who were recruited at the Toulouse University Hospital. These participants fulfilled the diagnostic criteria of developmental dyslexia according to the exclusionary definition adopted by ICD-10 Classification of Mental and Behavioral Disorders (WHO, 1993). Performance of the dyslexic participants on the experimental comparison task was compared to 12 control children matched for chronological age (CA-control) and 12 control children matched for reading age (RA-control). All control children attended regular primary schools or secondary education in the urban area of Toulouse (France). Reading age was estimated using the "Alouette" Reading test, a standardized test for French language (Lefavrais, 1967). All subjects had normal or corrected-to-normal visual acuity and no history of neurological or psychiatric disorders. The study was approved by the local Ethics' committee and informed written consent was obtained from the children and their parents.

The CA-control group (four girls; mean chronological age $=10.6$ years, $\mathrm{SD}=0.5$, range: $10.3-12$; mean reading age $=11.3$ years, $\mathrm{SD}=1.4$, range: $9.1-13.8)$ did not differ from the dyslexic group in chronological age $\left(t_{22}=1.27, p=0.218\right)$ but had a significantly higher reading age $\left(t_{22}=8.07, p<0.001\right)$.
The RA-control group ( 2 girls; mean chronological age $=7.4$ years, $\mathrm{SD}=0.4$, range: $6.5-7.9$; mean reading age $=7.7$ years, $\mathrm{SD}=0.4$, range: 7.3-8.4) was significantly younger than the dyslexic group $\left(t_{22}=13.91, p<0.001\right)$ but of similar reading age $\left(t_{22}=0.90\right.$, $p=0.379)$. The CA- and RA-control groups significantly differed in both chronological age $\left(t_{22}=17.52, p<0.001\right)$ and reading age $\left(t_{22}=8.04, p<0.001\right)$.

The dyslexic children and their RA-matched controls were administered tasks of word (regular and irregular) and pseudoword reading (from the ODEDYS, Jacquier-Roux et al., 2002). Their visual attention span abilities were estimated through the global report task. They were further administered the phoneme deletion tasks of the EVALEC test (Sprenger-Charolles et al., 2005) to estimate their phoneme awareness. In these tasks, they were asked to delete the first phoneme of CVC or CCV syllables and pronounce the remaining (VC or CV) syllable. Dyslexic participants' performance was further compared with the norms of CA-matched 5th grade children, taken from Bosse and Valdois (2009) for the reading and global report tasks, from the EVALEC for phoneme awareness (Table 1).

As shown in Table 1, the dyslexic participants performed very similarly as RA-controls on all tasks, except for the more difficult CCV phoneme awareness task on which their performance was significantly lower. When compared with norms of 5th grade children, reading accuracy was significantly lower and reading speed slower for both (regular and irregular) words and pseudo-words in the dyslexic group. Further, dyslexic participants identified and reported significantly fewer letters within strings than CAmatched controls in the global report task, thus showing a visual attention span disorder.

\section{EXPERIMENTAL TASK}

\section{A letter-string comparison task}

Participants performed a perceptual matching task, namely a letter-string comparison task inspired from the task used by Gomez et al. (2008) and initially designed by Ratcliff and colleagues (Ratcliff, 1981; Ratcliff and Hacker, 1981). The task requires the matching of one letter string against another without requiring any overt verbal report. It thus involves visual processing but no explicit phonological encoding. Subjects had to judge whether or not the two successively presented letter strings were strictly identical, i.e., made up of the same letters in the same position (e.g., FBSH, FBSH), or different. Differences were manipulated in two conditions: (i) a substitution condition in which identity was manipulated and two letters replaced (e.g., TSHF, TGHD) and (ii) a transposition condition in which letter position was manipulated through the transposition of two letters (e.g., RTGM, RMGT).

\section{Stimuli}

All stimuli consisted of horizontal arrays of four letters. The choice of four-letter strings was made following pilot experiments that showed ceiling effects for three letters but floor effects when using five-letter strings in the older group of typically developing readers. To explore context effects, three different types of stimuli were used: non-words (NW; i.e., unpronounceable consonant strings), pseudo-words (PW; i.e., legal and pronounceable 
Table 1 | Performance of dyslexic children (DYS) on the descriptive measures (mean, SD) as compared to reading age (RA) controls and 5th Grade (CA) norms.

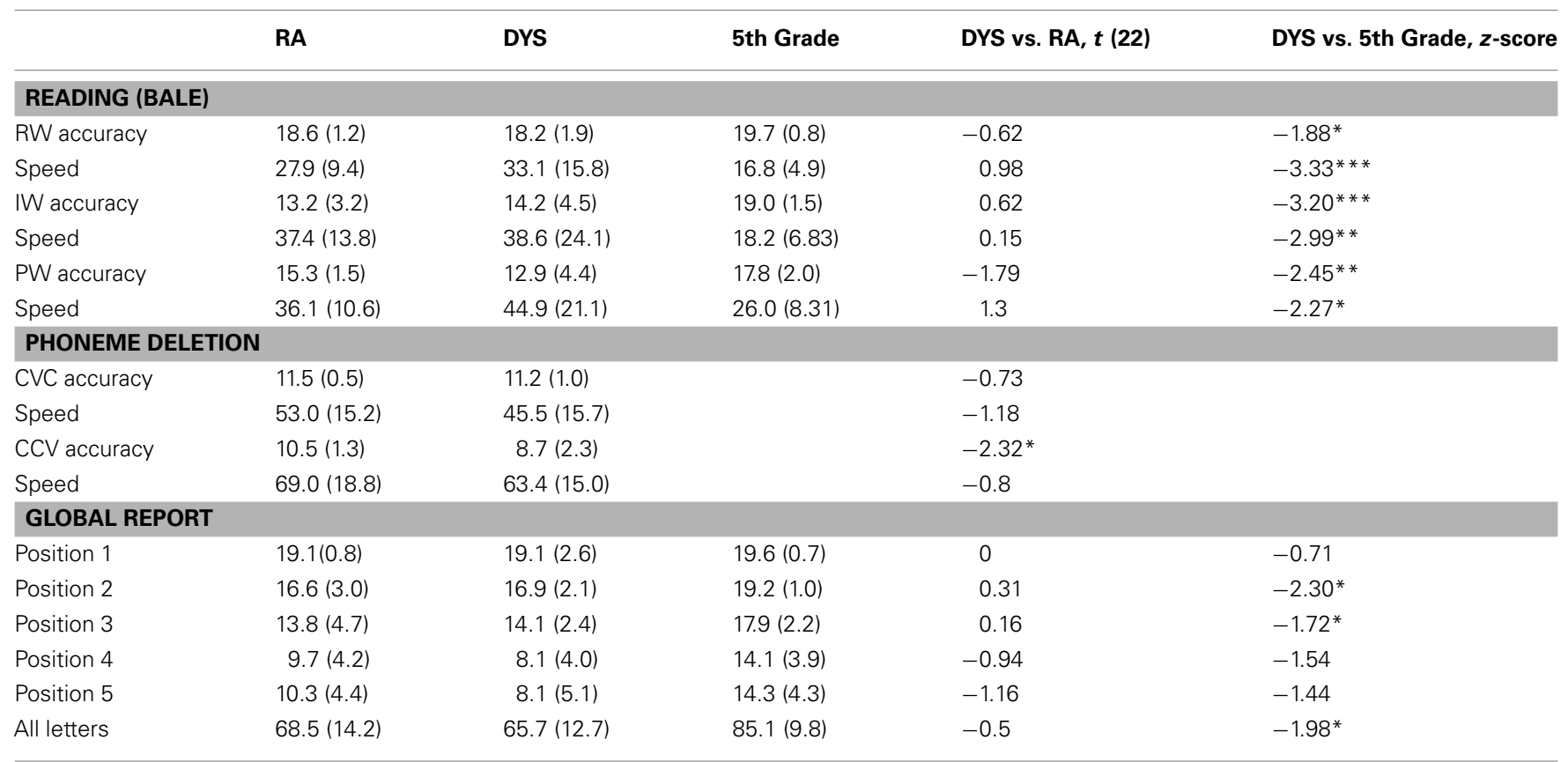

$R W$, regular word; IW, irregular word; $P W$, pseudo-word.

${ }^{*} p<0.05 ;{ }^{*} p<0.01 ;{ }^{*}{ }^{*} p<0.001$.

but meaningless letter sequences) and real words (W). Nonwords were constructed from 10 consonants (B, G, T, F, L, $\mathrm{M}, \mathrm{D}, \mathrm{S}, \mathrm{R}$, and $\mathrm{H})$. The strings contained no repeated letters (e.g., LFTD). Acronyms that might have been included in letter strings (e.g., HLM a very well-known acronym in France which refers to low rent apartment) or letter strings representing the skeleton of a real word (e.g., BLCN for "balcon" balcony) were avoided. Pseudo-words were built up using Lexique Toolbox (http://www.lexique.org/toolbox/toolbox.pub/index.php) with the constraint for each pseudo-word to form a pronounceable, orthographically legal letter string in French (e.g., BLOI, LERT, MIAT). Pseudo-words had no lexical neighbors so that any PSE, if observed, should be unambiguously interpreted as reflecting a sublexical influence. Words were selected such that either two letters could be changed or transposed to generate another four-letter word (e.g., "FACE" and "DAME" for letter substitution; "CAFE" and "FACE" for letter transposition).

Letter identity and letter position were manipulated so that consonants were replaced with consonants, vowels with vowels. Changes involved two letters within the string. They were equally distributed over string positions (1st and 2nd, 1st and 3rd, 1st and 4th, 2nd and 3rd, and so on).

The three categories of stimuli were assigned to three blocks of 84 experimental trials each. The order of presentation of the blocks was counterbalanced between participants. Each trial consisted of two visual stimuli presented briefly and sequentially. The two successive items of each experimental pair belonged to the same context category (e.g., two words, two pseudo-words, or two non-words) in order to rule out any lexical bias. In half of the trials $(N=42)$, the two successive strings were identical whereas they differed in the other half substitution or transposition of two letters in the second letter string). The order of stimuli was randomized within and between blocks.

\section{Procedure}

The experiment was performed using Presentation ${ }^{\circledR}$ software $\left(\right.$ Neurobehavioral Systems $\left.^{\odot}\right)$. The experimental blocks were preceded of 10 training trials during which participants received feedback. No feedback was given during the experimental blocks.

To avoid eyestrain, letters were presented in upper case (Arial, 24 ) in black on a gray background (RGB: 160, 160, 160). Spacing between adjacent letters was increased to minimize lateral masking (Pelli et al., 2004). All four-letter strings were flanked by two hashes. The array subtended an angle of approximately $3.4^{\circ}$.

At the beginning of each trial, a central fixation cross was presented for $1000 \mathrm{~ms}$ followed by a blank screen for $50 \mathrm{~ms}$. Then, a letter-string (NW, PW, or W) flanked by two hashes was displayed at the center of the screen for $200 \mathrm{~ms}$. The stimulus was immediately followed by a pattern mask of six hashes (\# \# \# \# \#), which lasted for $100 \mathrm{~ms}$ on the screen. After a 200-ms blank screen, a second letter string was displayed for $200 \mathrm{~ms}$ (see Figure 1). This second string was either identical to or different from the first one. Participants had to press a button with their right or left hand to indicate whether the two sequentially presented strings were "identical or not." The lateralization of response buttons was randomized between participants in order to control for dominant hand effects.

Percentage of correct responses and response latency were analyzed. Latency was measured from the second string onset until the participant's response. Any trial on which a subject made an 


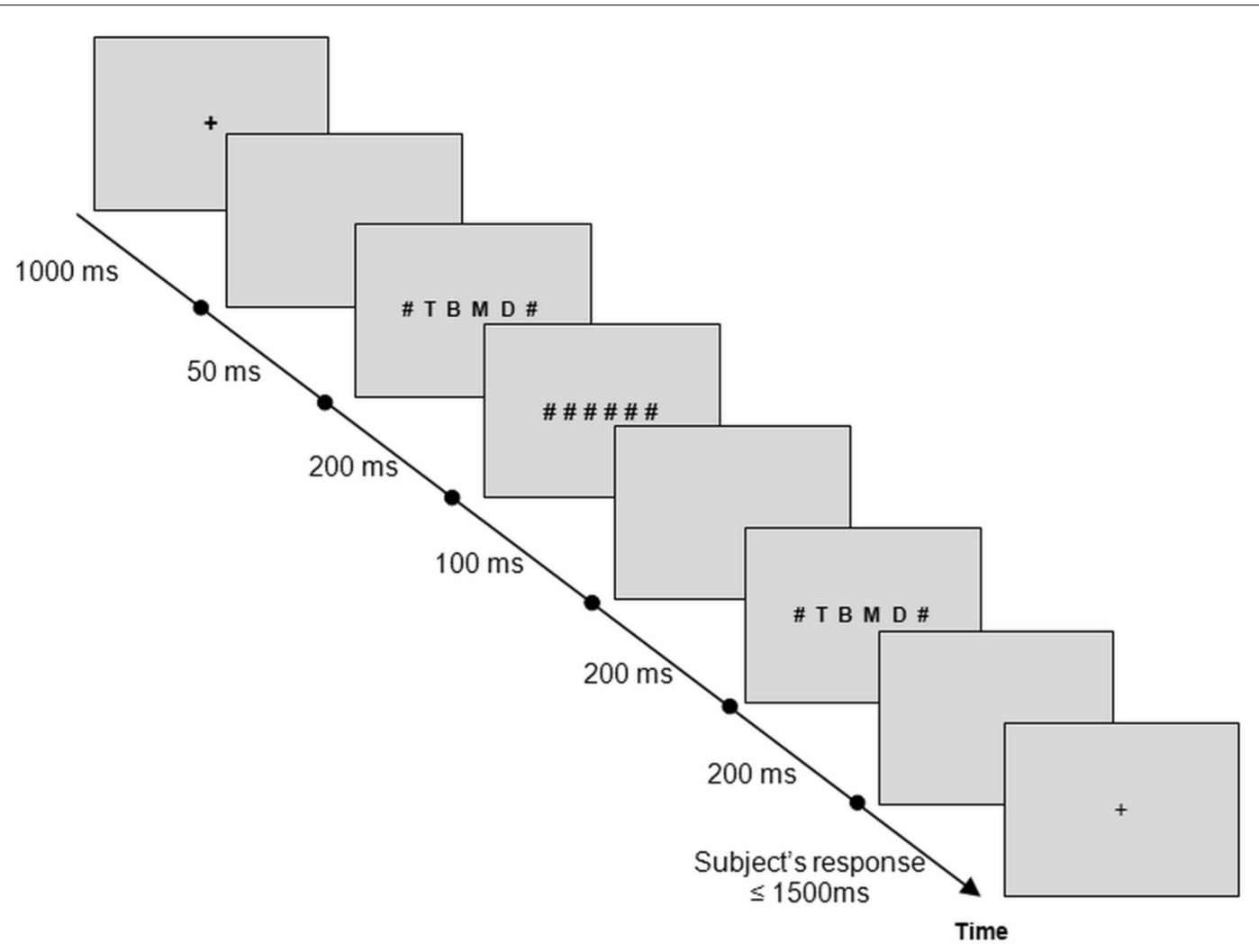

FIGURE 1 | Schematic representation of the string comparison paradigm.

error was excluded from the response latency analysis. All analyses were performed using Statistica 8 software (@StatSoft).

\section{RESULTS}

We conducted a first global ANOVA on correct responses (see Table 2) and reaction times (see Table 3 ) with Group (RA-controls vs. CA-controls vs. dyslexics) as between-subjects factor, Stimulus (NW vs. PW vs. W), and Similarity (identical pairs vs. different pairs because of substituted or transposed letters) as withinsubjects factors. The analysis showed a significant effect of Similarity on response accuracy with better performance on matched than unmatched pairs $\left(F_{1,33}=31.15, p<0.001\right)$ regardless of stimulus type $\left(F_{2,66}=4.71, p=0.012\right.$; NW: $p<0.001$; PW: $p<0.001, \mathrm{~W}$ : $p<0.001)$. The "Similarity $\times$ Group" interaction failed to reach significance $\left(F_{1,33}=2.78, p=0.078\right)$. The three groups showed similar performance on the matched pairs $\left(F_{1,33}=2.78\right.$; Tukey HSD test; Dyslexics vs. CA-controls, $p=0.988$; Dyslexics vs. RAcontrols, $p=0.594$; CA- vs. RA-controls, $p=0.233)$ whatever stimuli types $\left(F_{2,66}=4.71\right.$; Tukey HSD test; NW vs. PW, $p=0.691$; NW vs. W, $p=0.324$, PW vs. W, $p=0.991)$.

Results further showed shorter reaction times for matched pairs than unmatched pairs $\left(F_{1,33}=41.66, p<0.001\right)$ whatever the group $(F<1)$ and the type of stimuli $\left(F_{2,66}=3.72, p=0.029\right.$; NW: $p=0.043$; PW: $p<0.001, \mathrm{~W}: p<0.001)$. Reaction times on identical pairs were similar between groups (Tukey HSD test; Dyslexics vs. CA-controls, $p=0.965$, Dyslexics vs. RA-controls, $p=0.999$; CA-controls vs. RA-controls, $p=0.845$ ).
Given the high and similar performance on identical pairs across groups, the following analyses focused on the unmatched pairs only, i.e., those that differ by two substituted or transposed letters. Data were corrected with Arcsinus transformation so that all variables had normal distribution. ANOVAs were used to compare accuracy scores and response latencies with Group (RA-controls vs. CA-controls vs. dyslexics) as between-subjects factor, Stimuli (non-words vs. pseudo-words vs. words), and Condition (substitution vs. transposition) as within-subjects factors. Tukey HSD test were used for planned comparisons. The mean percentages of correct letter-string comparison scores as a function of Condition, Stimuli, and Group are shown in Figure 2 and Table 4. Latencies obtained for these data are provided in Table 5.

\section{RESPONSE ACCURACY ON UNMATCHED PAIRS}

There was a main effect of Group $\left(F_{2,33}=10.49, p<0.001\right)$ on letter-string comparison scores. The dyslexic participants showed lower performance than CA-controls $(p=0.001)$ but performed as RA-controls ( $p=0.999$; RA-controls vs. CA-controls, $p=0.003)$. Analysis showed a main effect of Stimuli $\left(F_{2,66}=28.55, p<0.001\right)$. Non-words were processed less efficiently than either pseudowords $(p<0.001)$ or words $(p<0.001)$ which were similarly processed $(p=0.613)$. The "Group $\times$ Stimuli" interaction was significant $\left(F_{4,66}=4.26, p=0.004\right)$. Planned comparisons indicated that both dyslexic participants and CA-controls showed a WSE (W $>$ NW; respectively 66.9 vs. $54.4 \%, p=0.007$ and 89.5 vs. 
Table 2 | Percentage of correct responses for dyslexic children.

\begin{tabular}{|c|c|c|c|c|c|c|}
\hline & \multicolumn{2}{|c|}{ Non-word } & \multicolumn{2}{|c|}{ Pseudo-word } & \multicolumn{2}{|c|}{ Word } \\
\hline & $\begin{array}{l}\text { Matched pairs } \\
\text { (SD), min-max }\end{array}$ & $\begin{array}{l}\text { Unmatched pairs } \\
\text { (SD), min-max }\end{array}$ & $\begin{array}{l}\text { Matched pairs } \\
\text { (SD), min-max }\end{array}$ & $\begin{array}{l}\text { Unmatched pairs } \\
\text { (SD), min-max }\end{array}$ & $\begin{array}{l}\text { Matched pairs } \\
\text { (SD), min-max }\end{array}$ & $\begin{array}{l}\text { Unmatched pairs } \\
\text { (SD), min-max }\end{array}$ \\
\hline Dyslexics & $\begin{array}{l}83.3(10.9) \\
61.9-95.2\end{array}$ & $\begin{array}{l}54.4(11.1) \\
40.5-73.8\end{array}$ & $\begin{array}{l}83.5(11.6) \\
54.8-92.9\end{array}$ & $\begin{array}{l}67.9(14.4) \\
47.6-92.5\end{array}$ & $\begin{array}{l}85.3(10.0) \\
69.0-97.6\end{array}$ & $\begin{array}{l}66.9 \text { (14.3) } \\
47.6-90.5\end{array}$ \\
\hline RA-controls & $\begin{array}{l}71.0(14.7) \\
52.4-97.6\end{array}$ & $\begin{array}{l}57.3(15.1) \\
35.7-83.3\end{array}$ & $\begin{array}{l}80.2(12.0) \\
50.0-95.2\end{array}$ & $\begin{array}{l}68.1(15.3) \\
47.6-95.2\end{array}$ & $\begin{array}{l}80.0(10.5) \\
61.9-92.9\end{array}$ & $\begin{array}{l}63.3(11.1) \\
50.0-88.1\end{array}$ \\
\hline
\end{tabular}

RA-controls, and CA-controls obtained on matched and unmatched pairs for non-word, pseudo-word, and word stimuli in the letter-string comparison task.

Table 3 | Mean reaction times (in $\mathbf{m s}$ ) of dyslexic children.

\begin{tabular}{|c|c|c|c|c|c|c|}
\hline & \multicolumn{2}{|c|}{ Non-word } & \multicolumn{2}{|c|}{ Pseudo-word } & \multicolumn{2}{|c|}{ Word } \\
\hline & $\begin{array}{l}\text { Matched pairs } \\
\text { (SD), min-max }\end{array}$ & $\begin{array}{l}\text { Unmatched pairs } \\
\text { (SD), min-max }\end{array}$ & $\begin{array}{l}\text { Matched pairs } \\
\text { (SD), min-max }\end{array}$ & $\begin{array}{l}\text { Unmatched pairs } \\
\text { (SD), min-max }\end{array}$ & $\begin{array}{l}\text { Matched pairs } \\
\text { (SD), min-max }\end{array}$ & $\begin{array}{l}\text { Unmatched pairs } \\
\text { (SD), min-max }\end{array}$ \\
\hline Dyslexics & $\begin{array}{l}931.1(247.0) \\
618.5-1595.8\end{array}$ & $\begin{array}{l}973.0(255.9) \\
726.0-1656.6\end{array}$ & $\begin{array}{l}845.6(170.2) \\
687.6-1301.6\end{array}$ & $\begin{array}{l}948.6(181.3) \\
633.8-1219.5\end{array}$ & $\begin{array}{l}865.6(210.5) \\
591.6-1374.2\end{array}$ & $\begin{array}{l}1000.6(254.1) \\
717.8-1500.3\end{array}$ \\
\hline RA-controls & $\begin{array}{l}978.4(217.4) \\
665.3-1430.9\end{array}$ & $\begin{array}{l}1079.0(179.7) \\
863.7-1413.5\end{array}$ & $\begin{array}{l}928.5(248.6) \\
572.2-1552.6\end{array}$ & $\begin{array}{l}1000.3 \text { (145.9), } \\
744.4-1190.1\end{array}$ & $\begin{array}{l}928.6(197.0) \\
680.3-1245.9\end{array}$ & $\begin{array}{l}1068.8 \text { (201.3), } \\
741.3-1387.8\end{array}$ \\
\hline
\end{tabular}

RA-controls, and CA-controls obtained on matched and unmatched pairs for non-words, pseudo-words, and words in the letter-string comparison task.
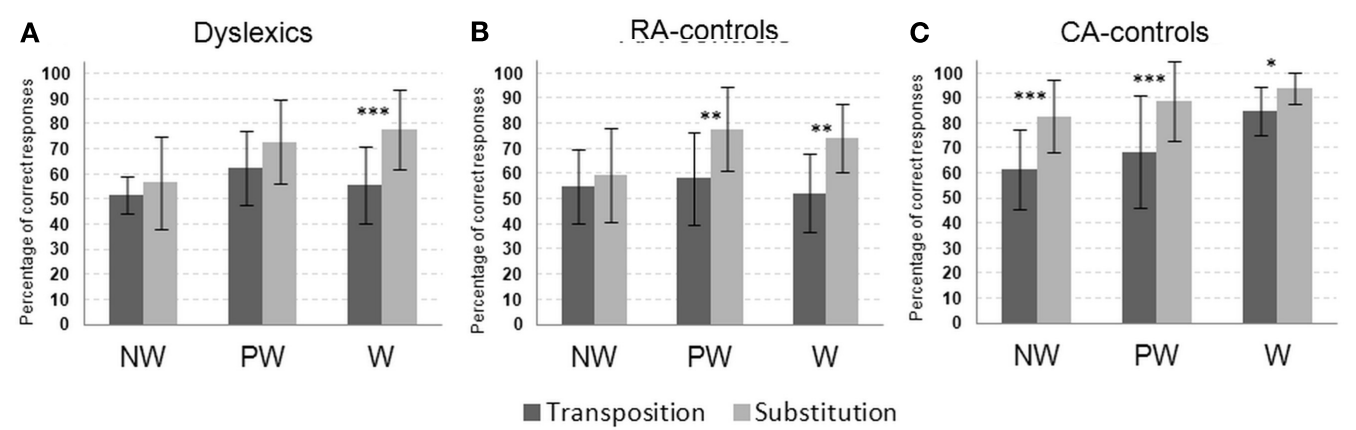

FIGURE 2 | Percentage of correct responses for dyslexic children (A), reading age controls (RA-controls) (B) and chronological age controls (CA-controls) (C) on non-word (NW), pseudo-word (PW),

$72.3 \%, p<0.001)$. A word advantage over pseudo-words was found in CA-controls only ( $\mathrm{W}>\mathrm{PW} ; 89.5$ vs. $78.9 \%, p=0.032$ ). Finally, the PSE (PW $>$ NW) was significant in the dyslexic (67.9 vs. $54.4 \%, p=0.009$ ) and RA-control groups (68.1 vs. $57.3 \%$, $p=0.021)$.

Moreover, there was a significant main effect of Condition $\left(F_{1,33}=70.45 ; p<0.001\right)$ with better performance in the substitution (e.g., LFTD/) than transposition (e.g., LFTD/LDTF) condition. The transposed-letter effect (transposition $<$ substitution) was found in all experimental groups ("Condition $\times$ Group," and word (W) stimuli for the transposition and substitution conditions of the letter-string comparison task. ${ }^{*} p \leq 0.05$; ${ }^{*} p \leq 0.01 ;{ }^{* *} p \leq 0.001$.

$F<1)$. The "Condition $\times$ Stimuli" interaction was significant $\left(F_{2,66}=3.83 ; p=0.027\right)$. Planned comparison showed a significant Stimuli effect in the substitution condition with lower performance on NWs as compared to legal pronounceable stimuli $(\mathrm{NW}<\mathrm{PW} / \mathrm{W} ; p<0.001)$. In the transposition condition, non-words were less efficiently discriminated than real words $(\mathrm{NW}<\mathrm{W} ; p=0.008)$. A tendency was observed to better discriminate pseudo-words than non-words (NW $<\mathrm{PW} p=0.054)$.

The "Group $\times$ Stimuli $\times$ Condition" interaction was significant $\left(F_{4,66}=3.31 ; p=0.016\right)$. Table 4 provides a summary of 
Table 4 | Word superiority effect (WSE).

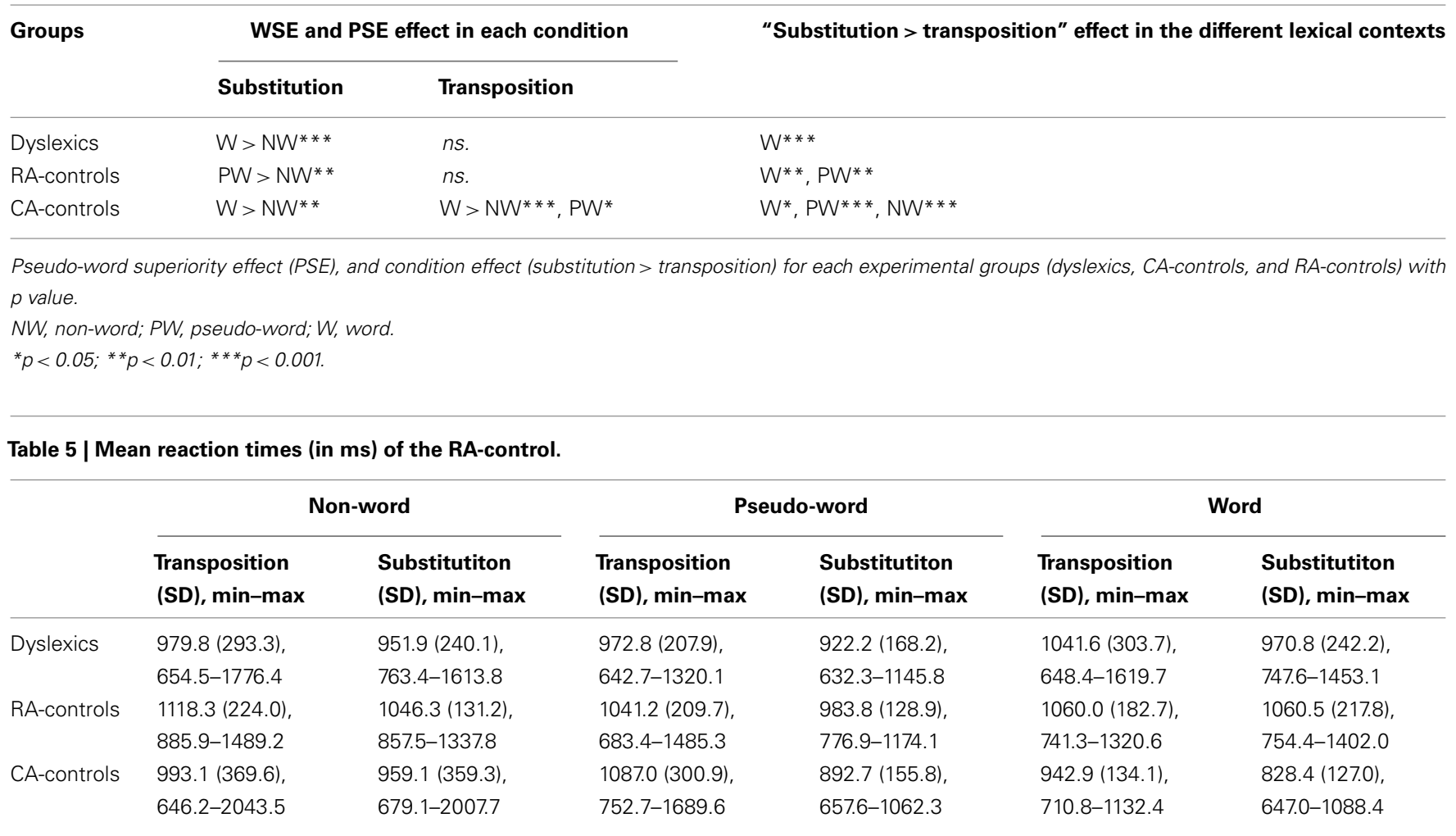

Dyslexic, and CA-control children (SD) for the transposition and substitution conditions and the different stimuli (non-word, pseudo-word, and word).

the interaction effects. CA-controls performed better in the Substitution than in the Transposition condition whatever Stimuli type - Non-Words: $p<0.001$; Pseudo-Words: $p<0.001$; Words: $p=0.041-$ whereas dyslexic children showed better Substitution than Transposition performance only for words (77.8 vs. 55.9\%, $p<0.001)$. RA-controls showed a substitution advantage for both pseudo-words ( 77.8 vs. $58.3 \%$ respectively, $p=0.002$ ) and words (74.2 vs. $52.4 \%$ respectively, $p=0.002$ ).

CA-controls showed a WSE over non-words for the substitution condition $(p=0.013)$ and over both non-words and pseudowords in the transposition condition $(p<0.001$ and $p=0.024$ respectively). Dyslexic children showed a significant WSE for the substitution condition ( $\mathrm{W}>\mathrm{NW} ; 77.8$ vs. $56.7 \%$ respectively; $p<0.001$ ) together with a trend for PSE (PW $>$ NW; 73.0 vs. $56.7 \%$ respectively; $p=0.066)$. RA-controls only showed a significant PSE for the substitution condition (PW $>$ NW; 77.8 vs. $59.5 \%, p=0.004)$.

Furthermore, detecting changes in the substitution condition was more difficult for dyslexic children than for CA-controls, specifically for non-words (56.7 vs. $82.9 \%$; LSD test: $p=0.035$ ). A trend toward the same effect was observed for both pseudo-words (73.0 vs. $89.0 \%, p=0.058$ ) and words ( 77.8 vs. $94.0 \%, p=0.070$ ). In the transposition condition, dyslexics performed less well than CA-controls for words (55.9 vs. $84.9 \%$, LSD test: $p=0.022$ ). RAcontrols performed as dyslexic children and had lower performance than CA-controls on word stimuli for both the substitution (74.2 vs. $94.0 \%$, LSD test: $p=0.026)$ and transposition (52.4 vs. $84.9 \%$, LSD test: $p=0.012$ ) conditions.

\section{RESPONSE LATENCY ON UNMATCHED PAIRS}

As for reaction times (see Table 5), neither main Group nor Stimuli effects or "Group $\times$ Stimuli" interaction were found.

A significant main effect of Condition was observed with shorter reaction times when two letters are substituted rather than transposed $\left(F_{1,33}=33.29 ; p<0.001\right)$. The significant "Condition $\times$ Group" interaction $\left(F_{2,33}=5.13 ; p=0.011\right)$ showed that the condition effect on RTs was only significant for CA-controls (893.4 vs. $1007.7 \mathrm{~ms} ; p<0.001$ ).

Neither the "Condition $\times$ Stimuli" interaction $\left(F_{2,66}=2.22\right.$; $p=0.116)$ nor the "Condition $\times$ Stimuli $\times$ Group" interaction $\left(F_{4,66}=2.18 ; p=0.081\right)$ were significant.

\section{DISCUSSION}

Results show that (1) the performance pattern of dyslexic children is impaired relative to CA-control children but is similar to that of RA-controls; (2) letter strings are better discriminated when two letters are substituted rather than transposed, in the dyslexic children as in the control groups; (3) A substitution advantage is found in CA-controls whatever stimulus type (although being weaker for words) but the effect is limited to words and pseudo-words in RAcontrols and is only found for words in dyslexic children; and (4) the impact of condition on stimuli effect depends on group: the substitution condition yielded a WSE $(\mathrm{W}>\mathrm{NW}$ ) in CA-controls and dyslexic children. A PSE (PW $>$ NW) was further found in RA-controls and to a lesser extent in the dyslexic group. The transposition condition induced a strong WSE ( W $>$ NW, PW) in CA-controls only. 


\section{LETTER-IDENTITY PROCESSING}

The current findings show that dyslexic children as beginning readers (e.g., RA-controls) are less prone than CA-controls at detecting substitutions across strings. Variations in letter substitution detection with grade and literacy instruction (RA vs. CA comparison) are in agreement with previous report of substitution priming effects in lexical decision tasks for beginning readers, but not for older children (Castles et al., 2007). Worse letter identification encoding in our comparison task for dyslexic children also reminds previous data using the Reicher-Wheeler paradigm (Grainger et al., 2003). The overall data suggests that dyslexic children have letter identity encoding problems. These problems are found whatever the nature of the letter string, thus suggesting that they originate from a pre-lexical level of processing. This hypothesis is also supported by the fact that dyslexic children showed both a WSE and a PSE over non-words but no WSE over pseudo-words in the substitution condition. The PSE over non-words suggests that letter identity encoding is sensitive to letter-string orthographic regularities. However, in the absence of WSE over pseudo-words, letter identity improvement in word context cannot be attributed to prior word recognition. Results rather suggest that the orthotactic information present in both words and pseudo-words facilitates letter identification in dyslexic children. This result is consistent with Grainger et al.'s (2003) findings in the ReicherWheeler task. Letter identification seems to be sensitive to the sub-lexical, orthographic structure of stimuli, so that orthographically legal letter sequences make letter identification easier than illegal sequences. Dyslexic children, as beginning readers, benefit from the facilitatory effects of orthotactic constraints rather than lexical properties for letter-identity processing. In support of this hypothesis, similar poor performance was found in dyslexic and RA-control children, thus in participants who exhibit similar visual attention span abilities but different phonology skills.

In our experimental paradigm, presentation time was constrained to force parallel processing. Indeed, the exposure duration of $200 \mathrm{~ms}$, which roughly corresponds to the mean duration of fixations in reading, is long enough for an extended glimpse, yet too short for a useful eye movement (Pelli et al., 2006). Thus, impaired performance on our comparison task suggests that beginning (RA) and dyslexic readers have difficulties for simultaneously encoding letter identity - even within relatively short four-letter strings - compared to older typically developing readers. This result reminds Hawelka and Wimmer's (2005) finding that dyslexic children can process two-element arrays like controls but have difficulties from the processing of four-element arrays. Overall, our findings are well in line with previous report of letter identification impairment in dyslexic individuals within either consonant strings (Hawelka and Wimmer, 2005; Hawelka et al., 2006; Bosse et al., 2007; Lassus-Sangosse et al., 2008; Ziegler et al., 2010) or words (Valdois et al., 2003, 2011). However, other deficits in multi-element processing have also been reported - for digit strings (Hawelka and Wimmer, 2005; Hawelka et al., 2006) and non-verbal strings (Pammer et al., 2004; Lobier et al., 2012). The letter-identity disorder found in our dyslexic participants might therefore reflect a reduction in the amount of attention that can be allocated in parallel across multi-elements within strings (Valdois et al., 2003; Bosse et al., 2007; Lassus-Sangosse et al., 2008). Further, it is worth noting how severe was the letter-identity encoding disorder in our dyslexic participants. Indeed in our categorization task, unmatched pairs differed by two letters out of four. The reported difficulty of dyslexic children and beginning readers to detect the substituted letters suggests that parallel letter identity encoding is highly challenging for beginning readers and fails to develop in dyslexic individuals.

Lastly, a substitution advantage over transpositions was found on all types of items (words, pseudo-words, and non-words) in CA-controls, as expected if their visual processing abilities allowed parallel processing of the entire letter string whatever the nature of the string to be processed. CA-controls further show a WSE suggesting lexical top-down influences on letter identity encoding. The absence of PSE in this group of skilled readers does not mean the absence of sub-lexical influences but rather suggests that they have acquired a level of reading that allows optimal performance on letter-identity encoding for both non-words and pseudo-words. The substitution advantage was only found on orthographically legal letter strings (words and pseudo-words) in the younger RA-matched children, suggesting a higher influence of context familiarity on substituted letter than transposed-letter detection. The substitution advantage over transpositions was only found for words in the dyslexic children suggesting that both letter identity and letter-position encoding were severely impaired and that better letter-identity processing was only found when the letter string was recognized as a real word.

\section{LETTER-POSITION ENCODING}

The current results highlight the higher difficulty (longer latencies and lower performance) for children, be they dyslexic or not, to encode letter order in comparison to letter identity, as respectively explored by the transposition and substitution conditions. This difficulty in transposition vs. substitution conditions is known as the transposed-letter effect and was often reported in studies using the masked priming lexical decision paradigm (Andrews, 1996; Perea and Lupker, 2004; Schoonbaert and Grainger, 2004; Acha and Perea, 2008).

In the current study, we used a different paradigm, a perceptual matching task, and we did not just focus on word processing. Our data show that the transposed-letter effect extends to pseudoword and non-word contexts, from a sufficient level of reading experience. Using a similar paradigm to study letter-position encoding, Gomez et al. (2008) showed a transposition disadvantage within word and non-word contexts in adult readers. It was further shown that beginning readers make more errors than intermediate and adult readers when reading aloud transposedletter pseudo-words as CHOLOCATE (Perea and Estévez, 2008). This suggests that the letter-position encoding process is subject to developmental changes (Castles et al., 2007; Acha and Perea, 2008). Our results support such an interpretation as the transposed-letter effect found on words diminishes with expertise in reading. Indeed dyslexic children, like RA-controls, show a stronger transposed-letter effect in word context than more skilled readers (CA-controls).

Our results further suggest a differential impact of lexical context on string processing with reading experience. The transposedletter effect is higher for non-words and pseudo-words than words 
in the group with the higher reading experience (CA-controls). A strong WSE (over NW and PW) on transpositions is further found in this group suggesting that letter-position encoding is subject to top-down lexical influences and is mainly inferred following word recognition. A similar top-down effect was reported by Gomez et al. (2008) in skilled adult readers. Without such topdown effects, skilled readers would be unable to read sentences composed of words whose inner letters have been re-arranged "wtih qutie anazimg esae" (Grainger and Whitney, 2004). In the absence of such influences, both dyslexic children and beginning readers are virtually unable to code letter-position information within strings.

Obviously, the older CA-matched children rather successfully encoded letter-identity information while they still found difficult to code letter-position within strings. This result suggests that letter identity and letter position are independently coded during letter-string processing. Data further suggest that letter identity may be extracted during the first stages of visual word processing but letter-position encoded at a later stage. This hypothesis is supported by the strong WSE we found on transpositions in CA-controls, which reflects top-down lexical influences. The time course of letter-identity and letter-position encoding within strings was directly addressed in adult participants using a lexical decision task while simultaneously recording event-related potentials (Mariol et al., 2008). Results showed that the waveforms around $200 \mathrm{~ms}$ were modulated by letter position and letter identity independently. This study however showed no time processing difference between the two encoding processes. Independent coding of letter identity and position is consistent with report of selective position encoding deficit in developmental dyslexia (Friedmann and Gvion, 2001). In the current study, both letter identity and letter-position encoding was altered in dyslexic children. Further research is required to determine whether letterposition encoding is systematically impaired when letter identity processing is not functional enough.

\section{GENERALIZATION TO THE DYSLEXIC POPULATION?}

Our data point to a strong letter-string processing disorder in dyslexic children. However, our dyslexic sample was characterized by a double cognitive disorder, both a visual attention span reduction and a phoneme awareness disorder. The phoneme awareness disorder is known to primarily affect normal acquisition of grapheme-phoneme mappings, thus resulting in poor pseudoword reading (Snowling, 2000). A phoneme awareness disorder is not expected to affect visual letter processing, so that phoneme

\section{REFERENCES}

Acha, J., and Perea, M. (2008). The effects of length and transposedletter similarity in lexical decision: evidence with beginning, intermediate, and adult readers. Br. J. Psychol. 99, 245-264.

Adelman, J. S., Marquis, S. J., and Sabatos-Devito, M. G. (2010). Letters in words are read simultaneously, not in left-toright sequence. Psychol. Sci. 21, 1799-1801.
Aghababian, V., and Nazir, T. A. (2000). Developing normal reading skills: aspects of the visual processes underlying word recognition. J. Exp. Child. Psychol. 76, 123-150.

Andrews, S. (1996). Lexical retrieval and selection processes: effects of transposed-letter confusability. J. Mem. Lang. 35, 775-800.

Besner, D., and McCann, R. S. (1987). "Word frequency and pattern distortion in visual word identification and production: an examination of

awareness disorders have been found in dyslexic children who showed no associated letter-string identification problems (Valdois et al., 2003; Bosse et al., 2007; Lallier et al., 2010; Peyrin et al., 2012). In contrast, a visual attention span disorder, i.e., a reduction in the amount of visual attention that can be allocated to multiple visual elements in parallel, is expected to prevent normal identification of letters within strings. It has been shown that poor visual attention span abilities not only affect letter- and digit-string processing (Ziegler et al., 2010; Valdois et al., 2012) but further extend to non-verbal tasks and non-verbal material. Indeed, Lobier et al. (2012) showed that dyslexic children with poor letter global report performance further showed similar impairments in categorization tasks in which strings of five non-alphanumeric elements (including geometrical shapes, pseudo-letters, and Japanese characters) were briefly displayed and participants asked to report how many elements from a target category they had previously seen. Evidence for a disorder regardless of element type suggests that the visual attention span disorder affects pre-orthographic multiple element processing. This is consistent with the current findings that letter identity encoding problems in our dyslexic sample occurs at a pre-lexical level of processing. The fact that our dyslexic participants used orthotactic information extracted from sub-lexical units rather than lexical information based on whole word processing is also compatible with their poor visual attention span abilities. It seems therefore premature to generalize the current findings to the whole dyslexic population. The heterogeneity of the dyslexic population is well recognized (Manis et al., 1996; Heim et al., 2008; Hadzibeganovic et al., 2010), so that findings from a small sample can hardly be generalized to the whole population. In particular, future studies are needed to investigate whether poor letter-identity encoding and poor letterorder processing primarily occur in the subset of dyslexic children characterized by poor visual attention span abilities or whether such difficulties can also be found in those dyslexic children who exhibit a single phonological disorder.

\section{ACKNOWLEDGMENTS}

This study was supported by a grant from the ANR (Research National Agency, Program Blanc "VASRA" no 07-BLAN-0019-01) to Sylviane Valdois. We thank Morgane Aubineau and Nathalie Faure-Marie for their help in data collection. We also thank the director and teachers of the Sermet elementary school (Toulouse, France). Finally, we address special thanks to the dyslexic and nondyslexic children who participated to this study for their time and motivation.

four classes of models," in Attention and Performance: The Psychology of Reading, ed. M. Coltheart (London: Lawrence Erlbaum Associates Ltd.), 201-219.

Bosse, M. L., Tainturier, M. J., and Valdois, S. (2007). Developmental dyslexia: the visual attention span deficit hypothesis. Cognition 104, 198-230.

Bosse, M. L., and Valdois, S. (2009). Influence of the visual attention span on child reading performance: a cross-sectional study. J. Res. Read.32, 230-253.

Castles, A., Davis, C., Cavalot, P., and Forster, K. (2007). Tracking the acquisition of orthographic skills in developing readers: masked priming effects. J. Exp. Child. Psychol. 97, 165-182.

Cattell, J. M. K. (1886). The time it takes to see and name objects. Mind 11, 63-65.

Chase, C. H., and Tallal, P. (1990). A developmental, interactive 
activation model of the word superiority effect. J. Exp. Child. Psychol. 49, 448-487.

Cunningham, A. E. (2006). Accounting for children's orthographic learning while reading text: do children self-teach? J. Exp. Child. Psychol. 95, 56-77.

Davis, C. J. (2001). The Self-Organising Lexical Acquisition And Recognition (SOLAR) Model Of Visual Word Recognition. ProQuest Information and Learning. University of New South Wales.

Dubois, M., De Micheaux, P. L., Noel, M. P., and Valdois, S. (2007). Preorthographical constraints on visual word recognition: evidence from a case study of developmental surface dyslexia. Cogn. Neuropsychol. 24, 623-660.

Dubois, M., Kyllingsbaek, S., Prado, C., Musca, S. C., Peiffer, E., LassusSangosse, D., and Valdois, S. (2010). Fractionating the multicharacter processing deficit in developmental dyslexia: evidence from two case studies. Cortex 46, 717-738.

Ellis, A. W., and Young, A. (1988). Human Cognitive Neuropsychology. London: Psychology Press Ltd.

Estes, W. K., and Brunn, J. L. (1987). Discriminability and bias in the word-superiority effect. Percept. Psychophys. 42, 411-422.

Feitelson, D., and Razel, M. (1984). Word superiority and word shape effects in beginning readers. Int. J. Behav. Dev. 7, 359-370.

Ferrand, L., and New, B. (2003). Syllabic length effects in visual word recognition and naming. Acta Psychol. (Amst.) 113, 167-183.

Friedmann, N., Dotan, D., and Rahamim, E. (2010a). Is the visual analyzer orthographic-specific? Reading words and numbers in letter position dyslexia. Cortex 46, 982-1004.

Friedmann, N., Kerbel, N., and Shvimer, L. (2010b). Developmental attentional dyslexia. Cortex 46, 1216-1237.

Friedmann, N., and Gvion, A. (2001). Letter position dyslexia. Cogn. Neuropsychol. 18, 673-696.

Friedmann, N., and Gvion, A. (2005). Letter form as a constraint for errors in neglect dyslexia and letter position dyslexia. Behav. Neurol. 16, 145-158.

Friedmann, N., and Rahamim, E. (2007). Developmental letter position dyslexia. J. Neuropsychol. 1, 201-236.

Gomez, P., Ratcliff, R., and Perea, M. (2008). The overlap model: a model of letter position coding. Psychol. Rev. 115, 577-600.

Grainger, J., Bouttevin, S., Truc, C., Bastien, M., and Ziegler, J. (2003). Word superiority, pseudoword superiority, and learning to read: a comparison of dyslexic and normal readers. Brain Lang. 87, 432-440.

Grainger, J., and Jacobs, A. M. (1994). A dual read-out model of word context effects in letter perception: further investigations of the word superiority effect. J. Exp. Psychol. Hum. Percept. Perform. 20, 1158.

Grainger, J., and Whitney, C. (2004). Does the human mind read words as a whole? Trends. Cogn. Sci. 8, 58-59.

Hadzibeganovic, T., Van Den Noort, M., Bosch, P., Perc, M., Van Kralingen, R., Mondt, K., and Coltheart, M. (2010). Cross-linguistic neuroimaging and dyslexia: a critical view. Cortex 46, 1312-1316.

Hawelka, S., Huber, C., and Wimmer, H. (2006). Impaired visual processing of letter and digit strings in adult dyslexic readers. Vision Res. 46, 718-723.

Hawelka, S., and Wimmer, H. (2005). Impaired visual processing of multielement arrays is associated with increased number of eye movements in dyslexic reading. Vision Res. 45, 855-863.

Heim, S., Tschierse, J., Amunts, K., Wilms, M., Vossel, S., Willmes, K., Grabowska, A., and Huber, W. (2008). Cognitive subtypes of dyslexia. Acta Neurobiol. Exp. (Wars.) 68, 73-82.

Hooper, D. A., and Paap, K. R. (1997). The use of assembled phonology during performance of a letter recognition task and its dependence on the presence and proportion of word stimuli. J. Mem. Lang. 189, 167-189.

Jacquier-Roux, M., Valdois, S., and Zorman, M. (2002). ODEDYS: Outil De Dépistage Des Dyslexies. Grenoble: Laboratoire Cogni-Sciences, IUFM de Grenoble.

LaBerge, D., and Brown, V. (1989). Theory of attentional operations in shape identification. Psychol. Rev. 96, 101.

LaBerge, D., and Samuels, S. J. (1974). Toward a theory of automatic information processing in reading. Cogn. Psychol. 6, 293-323.

Lachmann, T., and van Leeuwen, C. (2007). Paradoxical enhancement of letter recognition in developmental dyslexia. Dev. Neuropsychol. 31, 61-77.

Lallier, M., Donnadieu, S., Berger, C., and Valdois, S. (2010). A case study of developmental phonological dyslexia: is the attentional deficit in the perception of rapid stimuli sequences amodal? Cortex 46, 231-241.

Lassus-Sangosse, D., N'guyen-Morel, M. A., and Valdois, S. (2008). Sequential or simultaneous visual processing deficit in developmental dyslexia? Vis. Res. 48, 979-988.

Lefavrais, P. (1967). Manuel du Test de l'Alouette: Test D'analyse de la Lecture et de la Dyslexie. Éditions Du Centre De Psychologie Appliquée, Paris.

Lobier, M., Zoubrinetzky, R., and Valdois, S. (2012). The visual attention span deficit in developmental dyslexia is visual and not verbal. Cortex.

Manis, F. R., Seidenberg, M. S., Doi, L. M., Mcbride-Chang, C., and Petersen, A. (1996). On the bases of two subtypes of developmental [corrected] dyslexia. Cognition 58, 157-195.

Mariol, M., Jacques, C., Schelstraete, M. A., and Rossion, B. (2008). The speed of orthographic processing during lexical decision: electrophysiological evidence for independent coding of letter identity and letter position in visual word recognition. J. Cogn. Neurosci. 20, 1283-1299.

McClelland, J. L. (1976). Preliminary letter identification in the perception of words and nonwords. J. Exp. Psychol. Hum. Percept. Perform. 2, 80-91.

McClelland, J. L., and Rumelhart, D. E. (1981). An interactive activation model of context effects in letter perception: part I: an account of basic findings. Psychol. Rev. 88, 375.

Pammer, K., Lavis, R., Hansen, P., and Cornelissen, P. L. (2004). Symbolstring sensitivity and children's reading. Brain Lang. 89, 601-610.

Pelli, D. G., Burns, C. W., Farell, B., and Moore-Page, D. C. (2006). Feature detection and letter identification. Vision Res. 46, 4646-4674.

Pelli, D. G., Palomares, M., and Majaj, N. J. (2004). Crowding is unlike ordinary masking: distinguishing feature integration from detection. J. Vis. 4, 1136-1169.

Perea, M., and Estévez, A. (2008). Transposed-letter similarity effects in naming pseudowords: evidence from children and adults. Eur. J. Cogn. Psychol. 20, 33-46.

Perea, M., and Lupker, S. J. (2004). Can CANISO activate CASINO? Transposed-letter similarity effects with nonadjacent letter positions. J. Mem. Lang. 51, 231-246.

Pernet, C., Valdois, S., Celsis, P. and Demonet, J. F. (2006). Lateral masking, levels of processing and stimulus category: a comparative study between normal and dyslexic readers. Neuropsychologia 44, 2374-2385.

Peyrin, C., Lallier, M., Démonet, J. F., Pernet, C., Baciu, M., Le Bas, J. F., and Valdois, S. (2012). Neural dissociation of phonological and visual attention span disorders in developmental dyslexia: $\mathrm{fMRI}$ evidence from two case studies. Brain Lang.

Radach, R., Kennedy, A., and Rayner, K. (2004). Eye Movements and Information Processing During Reading. New York: Psychology Press.

Ratcliff, R. (1981). A theory of order relations in perceptual matching. Psychol. Rev. 88, 552.

Ratcliff, R., and Hacker, M. J. (1981). Speed and accuracy of same and different responses in perceptual matching. Percept. Psychophys. 30, 303-307.

Reicher, G. M. (1969). Perceptual recognition as a function of meaninfulness of stimulus material. J. Exp. Psychol. 81, 275-280.

Reitsma, P. (1983). Printed word learning in beginning readers. J. Exp. Child. Psychol. 36, 321-339.

Salmelin, R., Service, E., Kiesila, P., Uutela, K., and Salonen, O. (1996). Impaired visual word processing in dyslexia revealed with magnetoencephalography. Ann. Neurol. 40, 157-162.

Schoonbaert, S., and Grainger, J. (2004). Letter position coding in printed word perception: effects of repeated and transposed letters. Lang. Cogn. Process. 19, 333-367.

Share, D. L. (1999). Phonological recoding and orthographic learning: a direct test of the self-teaching hypothesis. J. Exp. Child. Psychol. 72, 95-129.

Snowling, M. J. (2000). Dyslexia. Oxford: Wiley-Blackwell.

Sprenger-Charolles, L., Colé, P., Béchennec, D., and Kipffer-Piquard, A. (2005). French normative data on reading and related skills from EVALEC, a new computerized battery of tests (end grade 1, grade 2 , grade 3, and grade 4) 1. Eur. Rev. Appl. Psychol. 55, 157-186.

Sprenger-Charolles, L., Siegel, L. S., and Bonnet, P. (1998). Reading and spelling acquisition in French: the role of phonological mediation and orthographic factors. J. Exp. Child. Psychol. 68, 134-165.

Terepocki, M., Kruk, R. S., and Willows, D. M. (2002). The incidence and nature of letter orientation errors in reading disability. J. Learn. Disabil. $35,214-233$. 
Valdois, S., Bidet-Ildei, C., LassusSangosse, D., Reilhac, C., N'GuyenMorel, M. A., Guinet, E., and Orliaguet, J. P. (2011). A visual processing but no phonological disorder in a child with mixed dyslexia. Cortex 47, 1197-1218.

Valdois, S., Bosse, M. L., Ans, B., Carbonnel, S., Zorman, M., David, D., and Pellat, J. (2003). Phonological and visual processing deficits can dissociate in developmental dyslexia: evidence from two case studies. Read. Writ. 16, 541-572.

Valdois, S., Bosse, M. L., and Tainturier, M. J. (2004). The cognitive deficits responsible for developmental dyslexia: review of evidence for a selective visual attentional disorder. Dyslexia 10, 339-363.

Valdois, S., Carbonnel, S., Juphard, A., Baciu, M., Ans, B., Peyrin, C., and Segebarth, C. (2006). Polysyllabic pseudo-word processing in reading and lexical decision: converging evidence from behavioral data, connectionist simulations and functional MRI. Brain Res. 1085, 149-162.

Valdois, S., Lassus-Sangosse, D., and Lobier, M. (2012). Impaired letter string processing in developmental dyslexia: what visual-tophonological code mapping disorder? Dyslexia.

Vidyasagar, T. R., and Pammer, K. (2010). Dyslexia: a deficit in visuospatial attention, not in phonological processing. Trends Cogn. Sci. (Regul. Ed.) 14, 57-63.

Wheeler, D. D. (1970). Processes in word recognition. Cogn. Psychol. 1, 59-85.

Whitney, C. (2001). How the brain encodes the order of letters in a printed word: the SERIOL model and selective literature review. Psychon. Bull. Rev. 8, 221-243.

Whitney, C. (2008). Comparison of the SERIOL and SOLAR theories of letter-position encoding. Brain Lang. 107, 170-178.
Whitney, C., and Lavidor, M. (2005). Facilitative orthographic neighborhood effects: the SERIOL model account. Cogn. Psychol. 51, 179-213.

WHO. (1993). The ICD-10 Classification of Mental and Behavioural Disorders: Diagnostic Criteria for Research. Geneva: World Health Organization.

Ziegler, J. C., and Jacobs, A. M. (1995) Phonological information provides early sources of constraint in the processing of letter strings. J. Mem. Lang. 34, 567-593.

Ziegler, J. C., Pech-Georgel, C. Dufau, S., and Grainger, J. (2010). Rapid processing of letters, digits and symbols: what purely visual-attentional deficit in developmental dyslexia? Dev. Sci. 13 F8-F14.

Conflict of Interest Statement: The authors declare that the research was conducted in the absence of any commercial or financial relationships that could be construed as a potential conflict of interest.

Received: 25 February 2012; accepted: 27 April 2012; published online: 21 May 2012.

Citation: Reilhac C, Jucla M, Iannuzzi S, Valdois S and Démonet J-F (2012) Effect of orthographic processes on letter identity and letter-position encoding in dyslexic children. Front. Psychology 3:154. doi: 10.3389/fpsyg.2012.00154

This article was submitted to Frontiers in Language Sciences, a specialty of Frontiers in Psychology.

Copyright (c) 2012 Reilhac, Jucla, Iannuzzi, Valdois and Démonet. This is an open-access article distributed under the terms of the Creative Commons Attribution Non Commercial License, which permits non-commercial use, distribution and reproduction in other forums, provided the original authors and source are credited. 